\title{
PROCESSO DE TRABALHO DA EQUIPE DE SAÚDE BUCAL NO MUNICIPIO DE NORDESTINA-BA
}

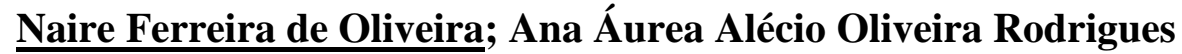 \\ 1. Bolsista PIBIC/CNPq, Graduando em Odontologia, Universidade Estadual de Feira de Santana, e-mail: \\ naire.ferreira@hotmail.com
}

2. Orientador, Departamento de Saúde, Universidade Estadual de Feira de Santana, e-mail: aleccio@terra.com.br

PALAVRAS-CHAVE: Trabalho; Saúde bucal; Território Sisal

\section{INTRODUÇÃO}

O processo de trabalho está ligado à forma como o sujeito atua na realização de uma atividade profissional com a finalidade de mudar um objeto, esse objeto pode ser uma matéria prima, um estado ou uma condição social ou pessoal. O processo de trabalho permeia não só o profissional, mas todos que tornam possível sua realização. No caso da saúde é preciso considerar que os consumidores do serviço são, também, sujeitos ou agentes do processo de trabalho e são, ainda, em alguma dimensão de seu ser, objetos desse mesmo processo de trabalho (FARIA, et. Al., 2009). O trabalho é um processo no qual os seres humanos atuam sobre as forças da natureza submetendo-as ao seu controle e transformando-as em formas úteis à sua vida, e nesse processo de intercâmbio, simultaneamente, transformam a si próprios (PEDUZZI; SCHRAIBER, 2006). Entender como ocorre o processo de trabalho em saúde permite compreender as condições de saúde da população onde esse processo ocorre, a partir desse entendimento é possível realizar mudanças, se necessárias, para alterar o cenário da saúde da comunidade.

O presente trabalho foi desenvolvido com o intuito de compreender como ocorre o trabalho da equipe de saúde bucal no município de Nordestina, munícipio pertencente ao território do Sisal. Por meio dos objetivos específicos buscamos entender como se organiza a oferta e demanda de serviços de saúde bucal nas unidades básicas de saúde no município e analisar as dificuldades enfrentadas pela equipe de saúde bucal no processo de produção do cuidado em saúde bucal.

O território do Sisal caracteriza-se como uma das regiões mais pobres do estado da Bahia e em consequência disso, enfrenta graves problemas socioeconômicos que repercutem na saúde dos habitantes da região, e, consequentemente, a saúde bucal da população é também afetada.

A realização desse trabalho foi motivada pela falta de informação sobre a situação de saúde dos munícipios do Sisal, ao se fazer um levantamento das 
bibliografias já produzidas sobre processo de trabalho, pouco se encontra sobre essa região, poucos pesquisadores se preocupam em estudar as regiões menos favorecidas e com isso não são apresentados dados de como se processa o trabalho em saúde nessas regiões.

\section{MATERIAIS E MÉTODOS}

Tipo e Natureza do Estudo- Para que houvesse a devida aproximação do objeto de estudo optou-se por uma abordagem qualitativa, crítica e reflexiva, que permitiu nos aproximar dos processos históricos que configuram os distintos padrões de relação entre Estado e sociedade, bem como as características dessa configuração no encaminhamento das propostas de mudança do setor saúde (TEIXEIRA, 1995).

Cenário da Pesquisa- $\mathrm{O}$ estudo foi realizado no município de Nordestina, tomando como cenário de estudo as Unidades Básicas de Saúde - Saúde da Família. Sujeitos do Estudo - Equipe de Saúde Bucal: Cirurgiões-dentistas, Auxiliar de Saúde Bucal (ASB) e Técnico de Saúde Bucal (TSB).

Técnicas de Coleta de Dados- Para coleta dos dados foi utilizada Entrevista semiestruturada, com roteiro orientador, complementada pela análise de documentos.

\section{RESULTADOS E DISCUSSÃO}

A apresentação dos resultados desse trabalho foi organizada a partir das categorias empíricas para facilitar a compreensão do processo de trabalho da equipe. As categorias são oferta $\mathrm{x}$ demanda, resolubilidade, trabalho desenvolvido, vínculo, trabalho em equipe, disponibilidade de materiais e motivação para trabalhar. Os dentistas foram identificados como CD1, CD2, CD3 e CD4. Os técnicos de saúde bucal foram identificados como TSB1 e TSB2. E o auxiliar de saúde bucal, identificada como ASB1.

OFERTA X DEMANDA- A oferta de serviços de saúde está relacionada à disponibilidade, ao tipo e à quantidade de serviços e recursos destinados à atenção à saúde; e demanda é a atitude do indivíduo de procurar serviços de saúde, obter acesso e se beneficiar com o atendimento recebido (RODRIGUES, 2005).

A organização das demandas parte do diagnóstico de problemas e do planejamento em saúde, dados epidemiológicos, por exemplo, podem auxiliar na disposição da demanda, é a partir da caracterização das necessidades da população que os atendimentos serão sistematizados, a demanda organizada se dá mediante marcação (BRASIL,2014). A demanda espontânea é o nome dado a qualquer atendimento não programado realizado na unidade de saúde, como os atendimentos de urgência, atendimento no qual não houve uma marcação prévia (PAULINO, 2014). No município de Nordestina as equipes de saúde bucal organizam a demanda por meio de marcação, maior parte do atendimento é oferecido à demanda organizada, e uma parcela menor é reservada à demanda espontânea. 
VÌNCULO- $O$ vínculo na atenção à saúde é a relação pessoal estreita e duradoura entre o profissional de saúde e o paciente, permitindo, com o passar do tempo, que os laços criados se estreitem e os mesmos se conheçam cada vez mais, facilitando a continuidade do tratamento, e consequentemente evitando consultas e internações desnecessárias. Em Nordestina, a equipe de saúde bucal relatou ter um bom vínculo com a comunidade e ressaltou a importância dos Agentes Comunitários de Saúde no fortalecimento desse vínculo.

TRABALHO DESENVOLVIDO- Os procedimentos clínicos realizados na unidade são os mais simples, todos os CDs afirmaram realizar exodontia, raspagem, limpeza e restauração. O CD1 e o CD4 e a ASB1 ressaltaram a realização de escovação supervisionada nos pacientes, o que é fundamental para prevenção e diminuição da incidência de muitas doenças bucais, como cárie e periodontite. O TSB2 afirmou realizar sala de espera, outro meio de grande importância para manter a comunidade informada sobre prevenção, diagnóstico e tratamento de muitas doenças, e a manutenção da saúde, visitas domiciliares e ações de convívio coletivo fora da unidade também são realizadas. $\mathrm{O}$ desenvolvimento do trabalho, muitas vezes, fica limitado pela falta de materiais e instrumentais, procedimentos básicos que poderiam ser realizados nas unidades de saúde, muitas vezes deixam de ser realizados no município de Nordestina por conta de problemas com a disponibilidade de materiais e instrumentais.

RESOLUBILIDADE- De acordo com o Ministério da Saúde, resolubilidade é a exigência de que, quando um indivíduo busca o atendimento ou quando surge um problema de impacto coletivo sobre a saúde, o serviço correspondente esteja capacitado para enfrentá-lo e resolvê-lo até o nível da sua competência (BRASIL, 2006). Nordestina não conta com o apoio de um Centro de Especialidades Odontológicas (CEO), um serviço que garante a resolubilidade dos problemas odontológicos que a unidade de saúde não tem capacidade de solucionar, sem a disponibilidade desse serviço pacientes que necessitam de atendimento especializado ficam desassistidos.

TRABALHO EM EQUIPE- O trabalho em equipe é um dos fatores que interferem no processo saúde-doença. A ação interdisciplinar pressupõe a possibilidade da prática de um profissional se reconstruir na prática do outro, ambos sendo transformados para a intervenção na realidade em que estão inseridos (ARAÚJO; ROCHA, 2007). Para o desenvolvimento de um bom trabalho, em qualquer setor, é necessário que se tenha uma equipe bem articulada, que todos trabalhem com o mesmo objetivo, uma equipe focada e bem gerida apresenta resultados satisfatórios, no município de Nordestina percebe-se por meio das falas da equipe de saúde bucal que a coordenação da saúde do município, apesar de nova, está engajada na busca de melhorias para a saúde do município, as ações realizadas pela equipe de saúde são definidas por meio de reuniões multidisciplinares mensais.

DIFICULDADES ENFRENTADAS PELAS EQUIPES- No município de Nordestina percebe-se que o trabalho multidisciplinar ainda falta ser aprimorado e que a falta de formação profissional ou treinamento dos Auxiliares de Saúde Bucal é um 
problema que preocupa os dentistas. A falta de materiais e instrumentais dificulta a realização do trabalho o que implica em um menor número de atendimentos e a não resolubilidade dos problemas, apresentados pelos pacientes, que demandam de tratamentos curativos. As mudanças na gestão do município interferem no processo de trabalho de forma negativa ao elevar a rotatividade dos profissionais, essa rotatividade enfraquece o vínculo dos usuários com a unidade de saúde. A rede de saúde do município não oferece resolubilidade para a demanda que depende de atendimento especializado. Formação profissional inadequada para atuar no SUS é uma das dificuldades apresentadas por Esposti e colaboradores (2006, pg. 50, 51), alguns profissionais com maior tempo de formação receberam uma formação tecnicista e biologicista, não voltada para os objetivos do SUS.

\section{CONSIDERAÇÕES FINAIS}

A realização da pesquisa teve seus objetivos alcançados a partir do momento que tornou possível o entendimento de como ocorre a dinâmica do processo de trabalho e mostrou as dificuldades enfrentadas na realização desse processo de trabalho. Apoio e uma boa gestão são indispensáveis na realização de um bom trabalho, em Nordestina os profissionais relataram ter esse apoio, afirmaram o fato de a gestão estar focada e ter uma boa articulação, as equipes realizam reuniões de planejamento e buscam trabalhar em conjunto, isso aponta que estão no caminho certo para solucionar as deficiências em saúde da comunidade. A educação em saúde é o principal caminho no desafio para alcançar maiores resultados na diminuição da incidência de doenças bucais nos moradores da comunidade, as equipes de saúde bucal de Nordestina demostraram estar focadas nessa questão, o que pode representar evolução das condições de saúde bucal da comunidade. Porém a alta rotatividade e a recente chegada da maioria dos profissionais de saúde ao município causam interferência no vínculo entre a comunidade e o serviço de saúde, o que consequentemente dificulta o processo de trabalho.

\section{REFERÊNCIAS}

ARAUJO, Marize Barros de Souza; ROCHA, Paulo de Medeiros. Trabalho em equipe: um desafio para a consolidação da estratégia de saúde da família. Ciênc. saúde coletiva, Rio de Janeiro, v. 12, n. 2, p. 455-464, Abril. 2007.

BRASIL. Ministério da Saúde. A Política Nacional de Saúde Bucal no Brasil: Registro de uma conquista histórica. Brasília, DF: Ministério da Saúde. 2006. Disponível em: http://189.28.128.100/dab/docs/publicacoes/geral/serie_tecnica_11_port.pdf. Acesso em: 02 mai. 2014. ESPOSTI. C. D. D. et. al. Perspectivas da saúde bucal na Estratégia Saúde da Família: dificuldades e avanços. UFES Rev. Odontol., Vitória, v.8, n.3, p.49-54, set./dez. 2006

FARIA, H. et. al., Processo de trabalho em saúde. Nescon UFMG, Editora Coopmed, Belo Horizonte, 2009.

PAULINO, J. A. Demanda espontânea x Demanda programada: Lidando com a procura maior que a oferta. Minas Gerais, 2014.

PEDUZZI, M.; SCHRAIBER, L. B. Processo de trabalho em saúde. In: Escola Politécnica de Saúde Joaquim Venâncio; Estação de Trabalho Observatório dos Técnicos em Saúde, (Org.). Dicionário da Educação Profissional em Saúde. Rio de Janeiro: EPSJV/Fiocruz, 2006. p. 199-206.

RODRIGUES, A. CONSTRUÇÃO DE SUJEITOS, SABERES E PRÁTICAS NA SAÚDE BUCAL DE ALAGOINHAS - BAHIA: o trabalho cotidiano no Programa de Saúde da Família como protagonista da mudança. Feira de Santana, 2005.

TEIXEIRA, C. Epidemiologia e planejamento de saúde. Salvador, 1995. 